\title{
EXPERIMENTAL INVESTIGATION OF EDM DIE SINKING PROCESS PARAMETERS ON ALUMINIUM ALLOY 5083 USING DESIGN OF EXPERIMENT
}

\author{
${ }^{1}$ Wahaizad Bin Safiei, ${ }^{2}$ Muhamad Ridzuan Bin Radin Muhamad Amin \\ ${ }^{1,2}$ Faculty of Engineering Technology, University Malaysia Pahang, 26300, Kuantan, Pahang, Malaysia \\ Iwahaizad@ump.edu.my \\ 2muhamadridzuan@ump.edu.my
}

\begin{abstract}
In this paper, the results of surface roughness (Ra) and material removal rate (MRR) are presented based on experimental studies of Electrical Discharge Machining (EDM) process parameters. Pulse ON time, pulse OFF time, peak current, gap voltage and jump speed are the selected input parameters and the experiments were conducted with Aluminium Alloy 5083 as a workpiece, copper as an electrode and the response variables are surface roughness (Ra) and material removal rate (MRR). Design of Experiment and Analysis of Variance (ANOVA) were applied to identify the optimum settings. The result shows that the significant factors for the value of surface roughness (Ra) and material removal rate (MRR) are pulses $O N$ time and peak current.
\end{abstract}

Index Terms- EDM Die sinking, Aluminium alloy, Copper electrode, Surface Roughness, Material Removal Rate.

\section{INTRODUCTION}

The Electrical Discharge Machining (EDM) is a common manufacturing process nowadays and widely used in many tool and die industries because of its capability to produce complicated geometries with superior accuracy. By definition, Electrical Discharge Machining (EDM) is an excellent material removal process using high thermal energy where electrical conductive material is eroded when electric discharge known as spark repeatedly striking the material. Hard and brittle materials such as Titanium Alloy, Mild Steel, and Carbon Steel can be machined easily. During EDM process, both the electrode and the workpiece are inundated in dielectric fluid such as paraffin oil and transformer oil. A small gap which is about $0.0125 \mathrm{~mm}$ to $0.125 \mathrm{~mm}$ between both electrode and workpiece should be maintained along the process. The discharge energy produces high thermal energy roughly more than $1200^{\circ} \mathrm{C}$ on the surface of the workpiece on the point of spark thereby causes local melting of metal. Subsequently, the particles of molten metal is flushed away by various techniques of jet flushing. This cycle repeats thousands of time per second (interval between sparks $\sim 100 \mu \mathrm{s})$. Therefore, some disadvantages effects in terms of mechanical and physical properties are detected especially at crater (small pocket). Basically, the main processing parameters will give significant effect on these properties. Obviously, process engineers can do their work in efficient way should the parameters for machining in EDM are optimized. Otherwise, the engineers will be busy do all unnecessary things just to get the optimum settings. Hence the process and the EDM machine can be rely as a routine equipment when this conditions are met, especially in mass production. Furthermore, higher productivity and faster product launch to market could be achieved. 


\section{LITERATURE REVIEW}

Dr. Navdeep Malhotra et al analyze the effect of machining parameter on surface roughness. From the study, it can be seen that peak current, pulse duration, pulse frequency and dielectric flow affecting the performance measures. From his findings, lower the value of current, the better the surface finish. This similar effect of the pulse on time on the surface finish are also observed [1].

Based on M.K Pradhan et al, the relationship between response surface roughness is valid for linear equation to the two main input parameters which are peak current and pulse on time. The optimum settings of surface roughness could be achieved if the parameters set at IP $=15 \mathrm{~A}$, Ton $=25$ $\mu \mathrm{s}$ and Toff $=100 \mu \mathrm{s}$ [2]. The effect of spark time on surface roughness, Ra is considered high when the power level is at $423 \mathrm{~kW}$. But the effect is considered low at the level of $118 \mathrm{~kW}$. Hence, it can be summarized that the effect on surface roughness Ra has the significant interaction between spark time and power [3].

The finding shows that gray relational analyses of experimental of electrode wear ratio, material removal rate, and surface roughness can convert optimization of the multiple performance responses into optimization of a single performance characteristic [4]. The surface roughness values are normally contributed by a pulse on time parameter and then followed by the peak current. The increasing value of interval time during machining process definitely can cause rough surface[5-6]. But according to S.H. Tomadi et al, the most significant factor affecting surface roughness was voltage. The pulse off time also observed as second important parameter in his study. Optimum surface roughness in machining for tungsten carbide was obtained at low values of peak current, pulse off time and voltage [7].

\section{RESEARCH METHODOLOGY}

The electric discharge machine, model Sodick AM3L was used to conduct the experiments. Copper (Melting point $=1083^{\circ} \mathrm{C}$, Density $=8.9 \mathrm{gms} / \mathrm{cc}$, Thermal conductivity $=268-389 \mathrm{Watt} / \mathrm{mK}$, Electrical conductivity $=57.59 \mathrm{ohm} / \mathrm{mm}$ ) was used as electrode and Aluminium Alloy 5083 was selected as the workpiece. The experiments performed under the designed fractional factorial procedure due to reduce the cost of experiment. The results of this study could be applied in selecting the optimum parameters thereby to get the desired EDM superior results of the responses. Minitab software was used to analyze the responses. Peak current, pulse ON time, pulse OFF time, gap voltage and jump speed are the EDM Die Sinking input parameters in the experiment. Table 1 shows the EDM process parameters and the two levels (low level and high level) for each factors. The surface roughness tester, model Mitutoyo SJ400 was used to measure the surface roughness. The hole is being fixed to $0.3 \mathrm{~mm}$ depth in the experiments and the processing time is captured during the machining process. The material removal rate (MRR) can be calculated using the equation (1):

MRR $=\underline{\text { Pre Machining Workpiece Weight }- \text { Post Machining Workpiece Weight }}$

Machining time

The main objective of this research is to study the optimal settings and to analyze the effects of the EDM Die Sinking parameters on the responses studied. For that reason, Design of Experiment (DOE) method and analysis of variance (ANOVA) were applied in the experiments. 
Table 1 EDM Input Parameters

\begin{tabular}{|c|c|c|c|}
\hline \multirow{2}{*}{ No. } & \multirow{2}{*}{ Factor } & \multicolumn{2}{|c|}{ Level } \\
\cline { 2 - 4 } & & Low & High \\
\hline 1 & Pulse ON Time & 20 & 180 \\
\hline 2 & Pulse Off Time & 10 & 80 \\
\hline 3 & Peak Current & 12 & 36 \\
\hline 4 & Servo Voltage & 40 & 60 \\
\hline 5 & Jump Speed & 5 & 20 \\
\hline
\end{tabular}

\section{RESULT AND ANALYSIS}

These experiments are conducted using fractional factorial design with five (5) factors with two (2) levels each. The $2^{5-1}$ experiment being run in three (3) replicates and the total experiments are 48 runs. The results of surface roughness and MRR are shown in Table 2. The ANOVA technique is used to analyze the results prior to decide the most influential parameters that affect the responses.

Table 2 Surface roughness and MRR value of EDM Die Sinking process

\begin{tabular}{|c|c|c|c|c|c|c|c|c|c|c|c|}
\hline \multirow{2}{*}{ Std Order } & \multirow{2}{*}{$\begin{array}{l}\text { PULSE- } \\
\text { ON TIME }\end{array}$} & \multirow{2}{*}{$\begin{array}{l}\text { PULSE- } \\
\text { OFF TIME }\end{array}$} & \multirow{2}{*}{$\begin{array}{c}\text { PEAK } \\
\text { CURRENT }\end{array}$} & \multirow{2}{*}{$\begin{array}{c}\text { SERVO } \\
\text { VOLTAGE }\end{array}$} & \multirow{2}{*}{$\begin{array}{l}\text { JUMP } \\
\text { SPEED }\end{array}$} & \multicolumn{3}{|c|}{$\mathrm{Ra}(\mu \mathrm{m})$} & \multicolumn{3}{|c|}{$\operatorname{MRR}(\mathrm{g} / \mathrm{min})$} \\
\hline & & & & & & 1 & 2 & 3 & 1 & 2 & 3 \\
\hline 1 & 20 & 10 & 12 & 40 & 20 & 5.5 & 5.6 & 4.9 & 0.031 & 0.025 & 0.029 \\
\hline 2 & 180 & 10 & 12 & 40 & 5 & 9.3 & 8.7 & 8.3 & 0.074 & 0.088 & 0.079 \\
\hline 3 & 20 & 80 & 12 & 40 & 5 & 5.2 & 5.9 & 5.8 & 0.060 & 0.064 & 0.064 \\
\hline 4 & 180 & 80 & 12 & 40 & 20 & 8.7 & 9.3 & 8.6 & 0.172 & 0.123 & 0.155 \\
\hline 5 & 20 & 10 & 36 & 40 & 5 & 6.4 & 6.2 & 7.4 & 0.053 & 0.049 & 0.046 \\
\hline 6 & 180 & 10 & 36 & 40 & 20 & 17.0 & 18.0 & 18.9 & 0.351 & 0.425 & 0.413 \\
\hline 7 & 20 & 80 & 36 & 40 & 20 & 6.4 & 9.5 & 9.6 & 0.177 & 0.152 & 0.159 \\
\hline 8 & 180 & 80 & 36 & 40 & 5 & 17.0 & 18.5 & 15.2 & 0.746 & 0.686 & 0.500 \\
\hline 9 & 20 & 10 & 12 & 60 & 5 & 6.4 & 5.3 & 5.2 & 0.023 & 0.032 & 0.024 \\
\hline 10 & 180 & 10 & 12 & 60 & 20 & 10.1 & 9.1 & 9.3 & 0.142 & 0.143 & 0.140 \\
\hline 11 & 20 & 80 & 12 & 60 & 20 & 4.8 & 5.1 & 5.7 & 0.049 & 0.052 & 0.052 \\
\hline 12 & 180 & 80 & 12 & 60 & 5 & 6.5 & 8.6 & 8.9 & 0.107 & 0.107 & 0.107 \\
\hline 13 & 20 & 10 & 36 & 60 & 20 & 7.2 & 8.5 & 7.6 & 0.111 & 0.143 & 0.125 \\
\hline 14 & 180 & 10 & 36 & 60 & 5 & 14.3 & 17.3 & 14.5 & 0.607 & 0.616 & 0.664 \\
\hline 15 & 20 & 80 & 36 & 60 & 5 & 7.7 & 8.6 & 7.7 & 0.130 & 0.135 & 0.136 \\
\hline 16 & 180 & 80 & 36 & 60 & 20 & 11.0 & 13.9 & 13.6 & 0.538 & 0.545 & 0.583 \\
\hline
\end{tabular}

Pareto chart in Figure 2 and 3 show the value of standardized effects for every responses. The significant factors can be defined by referring to the $\mathrm{P}$-value. Obviously, if $\mathrm{P} \leq 0.05$, the factors or two factors interaction can be classified as significant. Therefore, from data analysis, the significant factors that influencing the surface roughness value are pulse $\mathrm{ON}$ time, peak current and two interactions between peak current and pulse $\mathrm{ON}$ time. 


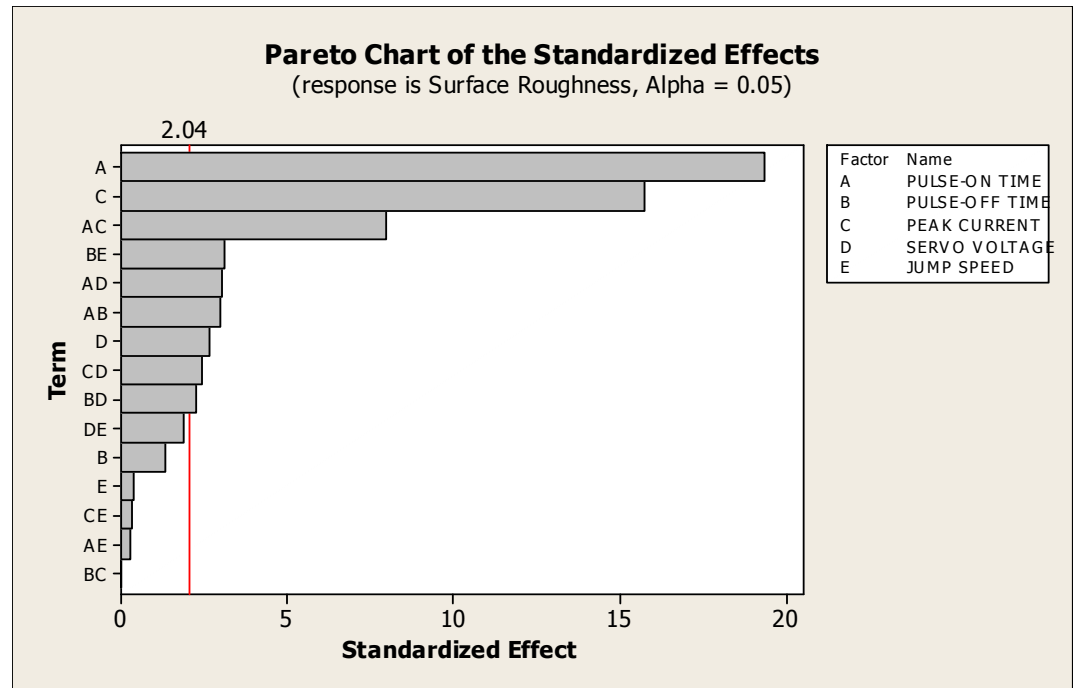

Figure 2 Pareto Chart of the Standardized Effects for Surface Roughness

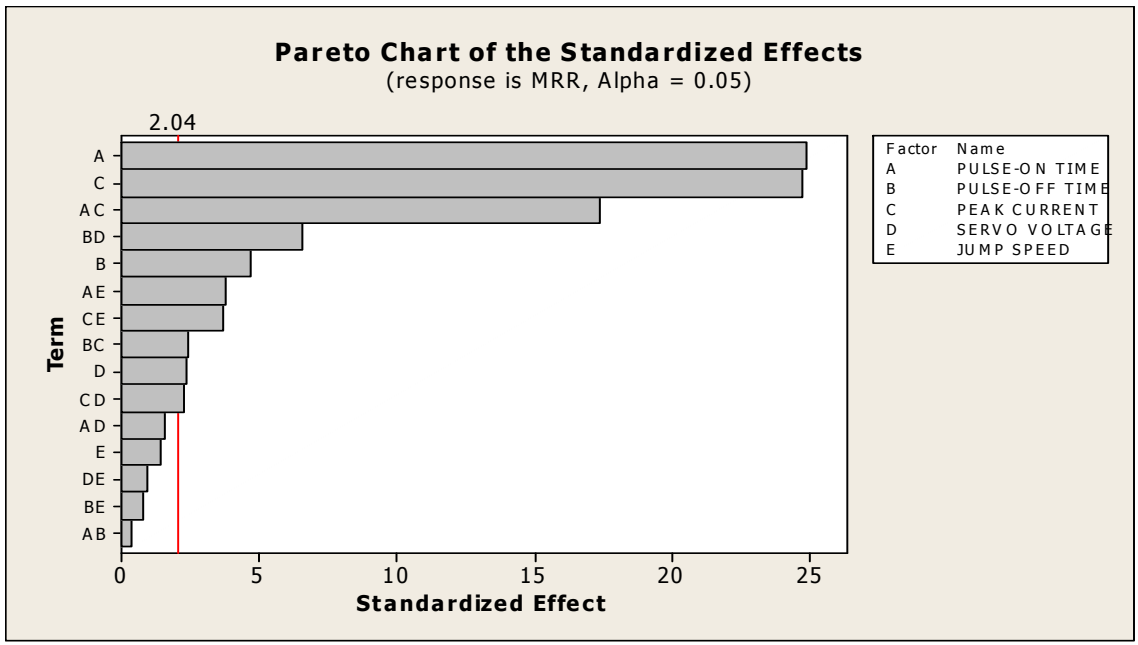

Figure 3 Pareto Chart of the Standardized Effects for MRR

Typically, graphical analysis or main effects plot also can be used to define optimum parameter settings for the responses studied. Figure 4 shows main effects plot for the factors that have significant influence to surface roughness and MRR. It can be seen that the significant interaction is an interaction between peak current and pulse ON time. While the interaction plot between peak current and pulse on time of both responses surface roughness and MRR are shown in Figure 5. 


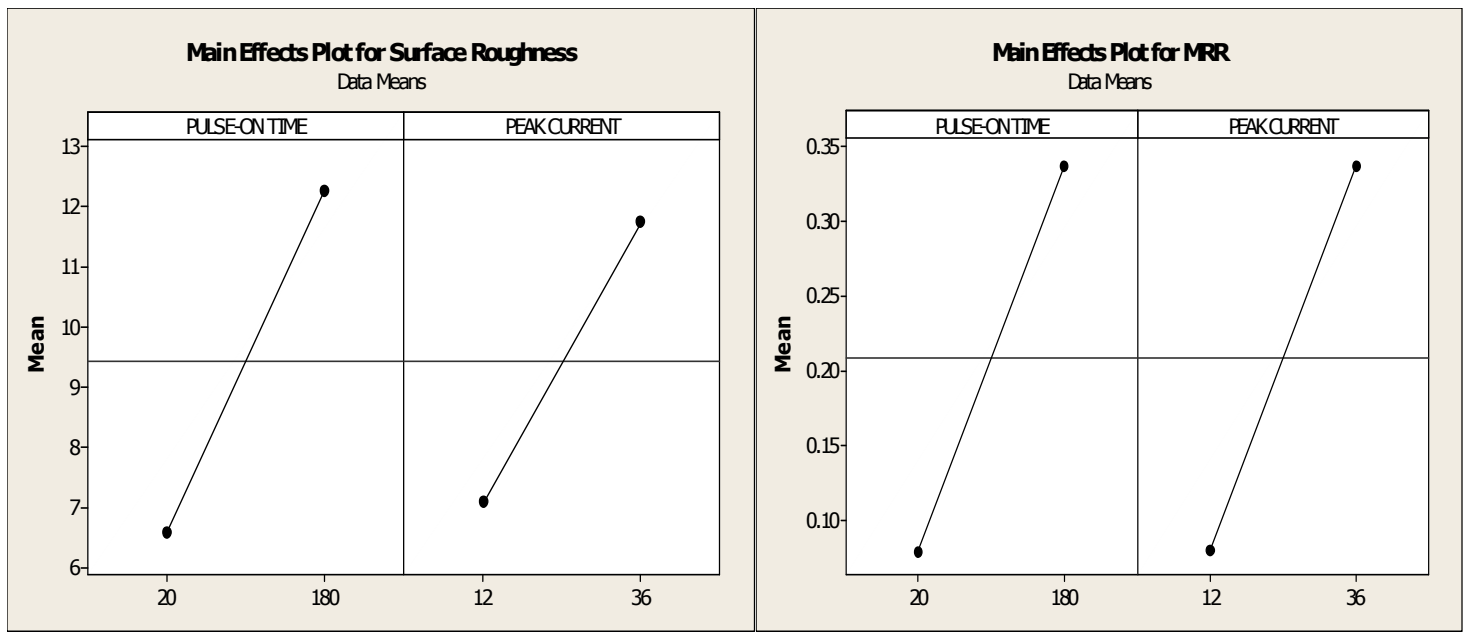

Figure 4 Main Effects Plot

Regression models can be defined as a mathematical model used to estimate the value of response at any changes of variables. Furthermore, the regression models also can be used to identify correlation and relationship among variables. Thus, the mathematical models can be used to find the best settings for the optimum response value. Predicted mathematical modeling can be developed using equation (2):

$$
\hat{y}=\widehat{\beta_{0}}+\widehat{\beta_{1}} X_{1}+\widehat{\beta_{2}} X_{2}+\cdots+\widehat{\beta_{n}} X_{n}
$$

which, $\beta$ : coefficient, $X$ : optimum factor

Predicted Equation for Surface Roughness

From the analysis, the linear equation below is the final model of coded factor for surface roughness $\left(\mathrm{R}_{\mathrm{a}}\right)$;

$$
\mathrm{R}_{\mathrm{a}}=9.4304+2.845 \mathrm{X}_{1}+2.3142 \mathrm{X}_{2}+1.1754 \mathrm{X}_{3}
$$

which, $\mathrm{X}_{1}$ : pulse ON time, $\mathrm{X}_{2}$ : peak current, $\mathrm{X}_{3}$ : pulse ON time * peak current

In order to get an optimum setting, the surface roughness should get a minimum value. Therefore supposedly the coded factors must be fixed at:-

$$
\mathrm{X}_{1} \rightarrow-\mathrm{ve}, \quad \mathrm{X}_{2} \rightarrow-\mathrm{ve}, \quad \mathrm{X}_{3} \rightarrow-\text {-ve }
$$

From the mathematical modeling, the predicted surface roughness value is $3.0958 \mu \mathrm{m}$. 


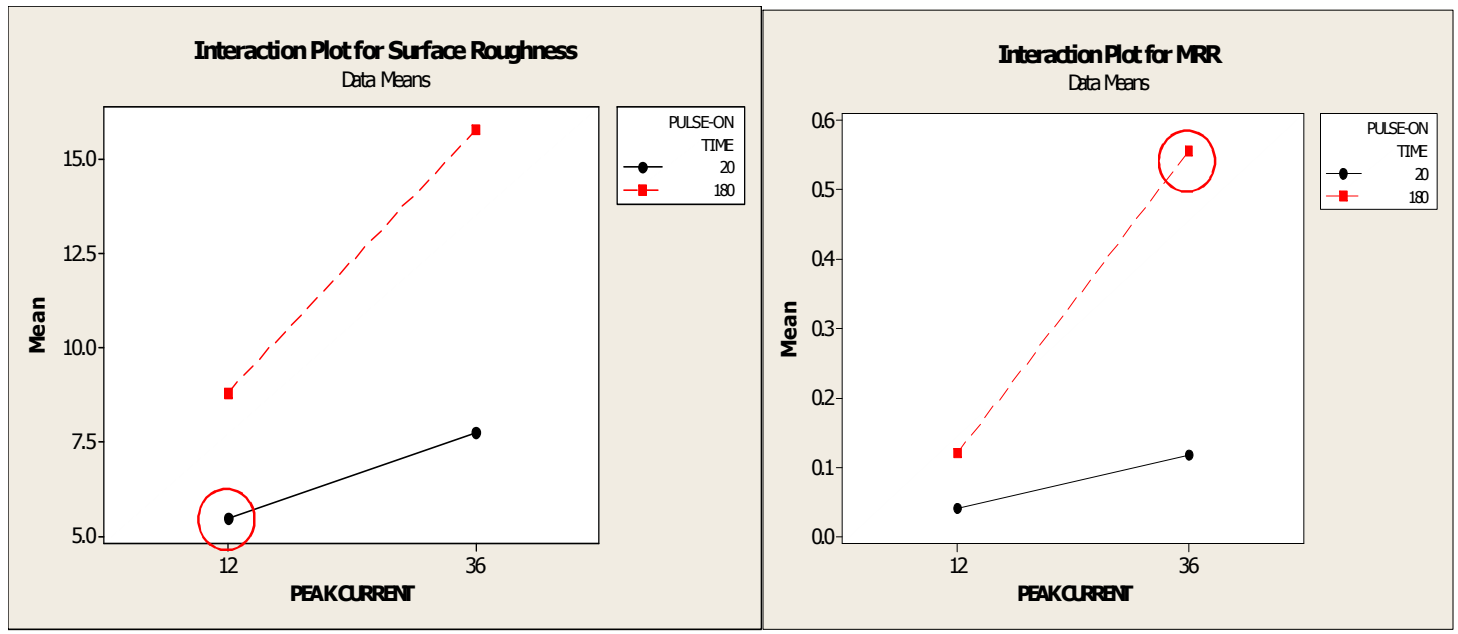

Figure 5 2-Way Interaction Plot

Predicted Equation for Material Removal Rate

From the analysis, the linear equation below is the final model of coded factor for material removal rate (MRR);

$$
\operatorname{MRR}=0.209+0.12896 \mathrm{X}_{1}+0.12808 \mathrm{X}_{2}+0.09012 \mathrm{X}_{3}
$$

which, $\mathrm{X}_{1}$ : pulse ON time, $\mathrm{X}_{2}$ : peak current, $\mathrm{X}_{3}$ : pulse ON time * peak current

In order to get an optimum setting, the material removal rate should get a maximum value. Therefore supposedly the coded factors must be fixed at:-

$$
\mathrm{X}_{1} \rightarrow+\mathrm{ve}, \quad \mathrm{X}_{2} \rightarrow+\mathrm{ve}, \quad \mathrm{X}_{3} \rightarrow+\mathrm{ve}
$$

From the mathematical modeling, the predicted material removal rate value is $0.556160 \mathrm{~g} / \mathrm{min}$.

The main goal of this study is to find the significant factors that influence the response results based on two responses MRR and Ra. The results of MRR and Ra were analyzed with the help of Minitab software. From the results, it is obvious that MRR increased in linear interpolation with the increase of peak current. A higher current will produce a stronger spark with higher thermal energy that consequences produce more MRR. Moreover, it is also can be seen that Pulse-On Time also gives significant effect on MRR. A higher Pulse-On Time will produce more spark within interval time or in a cycle causing the rate of material is being removed become more faster. Obviously, that low surface roughness could be obtained when both peak current and Pulse-On time set at lower value. This causing more uniform sparks within the surface and results smoother surface. A higher current produces a stronger spark that makes a crater with higher depth. Consequently, the surface becomes rougher. However, the influence of Jump Speed, Voltage and Pulse-Off time input parameters on surface roughness are not significant in this study. Confirmation run was conducted in order to evaluate margin error between theoretically prediction and confirmation test results [11]. Basically, the objective of confirmation run is to evaluate whether the optimum parameters predicted were in allowable range. A total three confirmation tests had been carried out consists of three-run for entire inputs parameter. All the actual values are within $95 \%$ prediction interval (PI). 


\section{CONCLUSION}

The following conclusions can be made from this experimental study:-

- They are two dominant significant factors affecting the Ra and MRR which are Peak Current and Pulse-On Time.

- Pulse-Off time, Voltage and Jump Speed are not significant factors affecting material removal rate (MRR) and surface roughness (Ra).

- In order to get very good surface roughness, the parameter must set at low ( - ) for both Peak Current and Pulse-On Time.

- However, in contrast, prior to get high material removal rate (MRR), the input parameter must set at high $(+)$ for both Peak Current and Pulse-On time.

- Regression models for both surface roughness (Ra) and material removal rate (MRR) are developed which is valid for first linear equation.

- From confirmation run, the results show exactly same like predicted regression model for surface roughness $(\mathrm{Ra})$ and material removal rate (MRR).

\section{REFERENCES}

[1] Dr. Navdeep Malhotra et al, Optimization of Control parameters for surface roughness in side flushing form of Die Sink EDM, 2011.

[2] M.K Pradhan et al, Modelling and analysis of process parameters on Surface Roughness in EDM of AISI D2 tool steel by RSM Approach, 2009.

[3] Yusuf Keskin et al, An experimental study for determination of the effects of machining parameters on surface roughness in electrical discharge machining, 2005.

[4] J. L. Lin et al, The use of the orthogonal array with grey relational analysis to optimize the electrical discharge machining process with multiple performance characteristics, 2001.

[5] M. Kiyak et al, Examination of machining parameters on Surface Roughness in EDM of tool steel, 2007.

[6] M. Hafiz Helmi et al, Investigation of surface roughness and material removal rate on tool steel using brass and copper electrode for Electrical Discharge Grinding process, 2009.

[7] S.H. Tomadi et al, Analysis of the influence of EDM parameters on surface quality, material removal rate and electrode wear of tungsten carbide, 2009.

[8] S.H. Lee et al, Study of the effect of machining parameters on the machining characteristics in electrical discharge machining of tungsten carbide, 2001.

[9] Kun Ling $\mathrm{Wu}$ et al, Improvement of surface finish on SKD steel using electro discharge machining with aluminum and surfactant added dielectric, 2005.

[10] Y.H. Guu et al, Effect of electrical discharge machining on surface characteristics and machining damage of AISI D2 tool steel, 2003.

[11] Wahaizad et al, Analysis of Infra-Red Laser Power Process Using Response Surface Methodology, International Journal of Engineering Technology And Sciences, Vol.6 December 2016 pg 30-36. 